\title{
Mastering the Match: Recruiting a Successful Surgery Resident
}

\author{
Lauren M. Dudas ${ }^{1}$ (1) $\cdot$ Uzer S. Khan $^{2}$ (1) $\cdot$ David C. Borgstrom ${ }^{1}$
}

Accepted: 3 September 2021/Published online: 28 October 2021

(C) The Author(s), under exclusive licence to Springer Science+Business Media, LLC, part of Springer Nature 2021

\begin{abstract}
Purpose of Review The objective of general surgery residency is to produce competent surgeons. At a minimum this requires being procedurally and clinically capable and able to pass the board exams. Recruitment is designed to select those residents who can successfully do so. But there is more to being a successful resident than that. In this review, we attempt to define a "successful resident" and how to attract them to your program.

Recent Findings Resident applicants are still most concerned with matching to a program that will prepare them for a surgery career. Though there is variation of importance for different applicants, resident life, comradery, and relationships with faculty or mentors do factor into residency ranking. The program website remains the most utilized resource for applicants. However, social media (SM) has an increasing role in applicants' evaluation of a program. SM and the preinterview gathering seem to expose the subjective aspects of a program most effectively. Additional assessments evaluating personality, grit
\end{abstract}

This article is part of the Topical collection on Surgical Education.

Lauren M. Dudas

lauren.dudas@hsc.wvu.edu

Uzer S. Khan

Uzer.Khan@AHN.ORG

David C. Borgstrom

dcborgstrom@hsc.wvu.edu

1 Department of Surgery, Division of Trauma, Emergency Surgery \& Surgical Critical Care, West Virginia University, 1 Medical Center Drive, PO Box 9238, Morgantown, WV 26506, USA

2 Department of Surgery, Allegheny Health Network, Pittsburgh, PA, USA or career goals may assist in screening applicants for good "fit."

Summary In order to recruit successful residents, it is necessary to determine which applicant attributes are important to the program. Additionally, a program must maintain an updated website with clearly delineated resident expectations and program strengths. The screening and interview process must be maximized to target residents with career goals complimentary to available program opportunities. If $\mathrm{SM}$ is utilized, post should be frequent with relevant information pertaining to both resident life and educational or clinical opportunities.

Keywords Attrition - Residency applicant - Residency interview $\cdot$ Residency match $\cdot$ Resident selection criteria

\section{Defining Success and Establishing Program Goals}

The resident recruitment process is meant to select candidates who will ultimately become competent, practicing surgeons. Success can be defined as simply as that—being able to finish residency and pass boards. However, success as a surgery resident is not binary. There are multiple other factors that contribute to resident success and how we judge it, such as research, leadership, teaching, international medical work and progression to fellowship if desired. Each program must determine what attributes are most important to the program in order to establish and make known the expectations for its residents.

At the most basic level, a successful resident is one who completes residency. The attrition rate for general surgery residency hovers around 20\%. Though there are various reasons for leaving a program, the majority leave for lifestyle reasons $[1,2]$. One explanation is that residents have 
inadequate exposure to surgery as students. In a survey evaluation of general surgery interns entering training in the 2007-2008 academic year, Abelson et al. concluded "categorical general surgery interns with more realistic expectations of surgery residency and life as an attending surgeon are more likely to complete training" [3]. This does not necessarily mean longer time spent on surgery rotations, but the quality of the experience [4]. A different explanation is the "surgeon personality." Students pursuing surgery and surgery residents consistently score higher on conscientiousness and extraversion. This has been demonstrated in multiple studies using a variety of personality tests [5-7]. Students pursuing surgery differ somewhat from residents in regards to openness to ideas, indicating some assimilation to peers during the training process. Using a different assessment, the World of Work Inventory Online, faculty and high performing residents had similar profiles, in contrast to low performing residents [8]. Burkhart et al. suggested grit, defined as "perseverance and passion for long-term goals," could be used as a surrogate for risk of attrition by screening applicants with an eight question survey [9]. This was found to remain significant when used to assess residents [10]. Furthermore, in a single institution study evaluating grit scores and the big five personality traits together compared to information available in the resident application suggested that non-low performing residents "possess unique, measurable personality traits and that the commonly used evaluation methodology does not identify them" [11]. It appears that using personality assessments to potentially stratify residents at risk for attrition may be a beneficial tool.

Being able to pass the boards is the next basic tenet of surgery resident success. Information in surgery candidate applications has been evaluated to determine if there is a correlation with resident performance on further standardized testing, namely American Board of Surgery (ABS) InTraining Examination (ABSITE) score and the ABS qualifying and certifying examinations. In summary, these studies compared at least some of the following components: United States Medical Licensing Examination (USMLE) step I or II scores, ABSITE scores, passing the ABS qualifying and certifying exam on the first attempt, and demographics. The conclusions were that there is significant correlation with performance on the ABSITE and passing general surgery boards [12, 13]. Additionally, there is a positive association between USMLE step II and to a lesser extent step I, to ABSITE performance [12-16]. Therefore, it is reasonable to use the USMLE step scores to screen for residents who may have difficulty with passing the ABS qualifying or certifying exam. This is important to program directors as the Accreditation Council for Graduate Medical Education (ACGME) mandates minimum passing requirements to maintain program certification
[17]. However, none of these tests were designed to be utilized for this purpose. For that reason and multiple others, the USMLE step I score will soon be reported as pass/fail. This will make the screening process of resident selection more challenging, as stated eloquently by Dr. Rozenshtein on behalf of the Association of Program Directors in Radiology in her recent paper [18]. Gardner et al. suggested using an alternative assessment. In a multiinstitutional study, a questionnaire was sent to candidates electronically prior to offering an interview. The tool took an average of $35 \mathrm{~min}$ to complete and was comprised of a situational judgement test and questions about "perceived ideal training program attributes." Though the effectiveness of the test for programs or candidates was not evaluated, $97 \%$ of applicants completed the test, suggesting additional testing is a reasonable screening option [19].

In addition to objective measurements, clinical performance is another aspect of resident success, and possibly the most challenging to predict when assessing candidates [20]. In an 18 year review of residents' candidate information, ABSITE scores and clinical performance at a university program, Alterman et al. found that the interview score, USMLE step I score and reporting being a high achiever in athletics or art predicted academic and clinical success [21]. An older study was unable to find any specific predictors of success in admission folders, but did note that participation in team sports was a characteristic attributable only to highest resident performers [22]. Tolan et al. found overall competence was related to female gender, AOA status and number of honors received in medical school, while USMLE scores were predictive only of medical knowledge [23]. The interview process allows for the evaluation of subjective or non-cognitive applicant characteristics. In their literature review evaluating the residency interview, Stephenson-Famy et al. remarked "ideally, an applicant should be a good "fit" for the program, with a high likelihood of success and a low likelihood of problems." Additionally, they laid out interview qualities to improve reliability, including clear expectations of the resident, standardized interview questions and limiting single interviewers [24]. However, it is known that interviews can be biased and are inherently subjective [24-26]. When individuals, often program directors or department chairs, make adjustments to the rank list, which is created based on an objectified scoring, it may jeopardize the selection of successful residents [27].

There have been a few novel strategies to attempt to improve successful resident recruitment. In 2012, Farkas et al. had evaluated using a surgery-specific written exam on the day of interviews. As expected, there was significant correlation with candidates ABSITE scores as they progressed with residency, with higher correlation than either USMLE test [28]. However, the test was administered on 
the interview day, so it was still not used as a screening tool but was available when determining the rank list. At the University of Pennsylvania, a novel selection strategy was created that utilized standardized screening, a preinterview essay, decreased faculty participants with scripted interviews, and minimized adjusting of the rank list after committee agreement. The result was decreased resident attrition; the authors concluded this was due to improved identification of "candidates most likely to succeed" [29]. Other possible processes that may lead to selecting successful residents include incorporating a skills test into the process in addition to other preinterview assessments [20].

Overall, it is essential that a program prioritize the importance of different candidate attributes. Though there is some conformation in the top few characteristics [30], "matching applicant objectives with program opportunities is of critical importance to many of the challenges faced by general surgery residency programs" [31]. For example, programs with nearly $100 \%$ fellowship participation after residency would not likely benefit by targeting the same demographic of applicants as a program with a history of graduating residents bound to practice in rural areas. Hence programs should know and attempt to match the program's strengths to applicant career goals. That being said, "...while it is essential to recruit residents who are likely to meet existing standards, it is even better to identify and recruit those who will exceed these standards as they will benefit the program in many ways... and this may perpetuate the recruitment of high quality residents year after year" [20]

\section{Candidates' Priorities}

In order to attract successful residents, programs must also understand the needs of the applicants. In an attempt to elucidate these priorities, there have been multiple studies utilizing surveys of fourth year medical students during the application process. Phitayakorn et al. evaluated surgery applicants to competitive academic centers over nearly a decade and found that the most important factors were the program's ability to prepare residents for future training or position, resident esprit de corps, faculty availability and involvement in teaching, depth and breadth of faculty and variety of patients and clinical resources. Lifestyle factors, such as child care or call rooms, were ranked least important [32]. In another survey-based study comparing students pursuing surgery and current surgical junior residents in both the USA and Japan, there were similar findings-educational factors were the most important in selecting a particular program. These authors found the highest rated factors were educational program, clinical experience, faculty quality and in some subgroups, perception of resident happiness [33]. These more recent studies correlate with prior studies which had found resident satisfaction, diversity or volume of training experience and geography had been important factors prior to the ACGME duty hour requirement implementation [34]. Contrarily, there are studies that surveyed different populations of surgery applicants that found resident happiness/ quality of life or collegiality to be more important to respondents than educational objectives [35-37]. This emphasizes understanding the strengths of a specific residency program and targeting candidates that "fit."

The interview process was upturned during the last cycle due to the COVID-19 pandemic, and the lasting ramifications are yet to be appreciated. However, one thing is clear-social media (SM) and online presence has a new status in the process. The importance of program websites for applicants has been confirmed across specialties in prior literature. In fact, many residents use the website information not only to determine where to apply, but also in their interview and ranking decisions [38, 39]. Nonetheless, in studies that evaluated general surgery or specialty program websites, the majority were found to be incomplete or outdated, have non-functional links and be overall inadequate $[31,39,40]$. In a review of programs' website specifically looking at elements of diversity, $89 \%$ missed the mark for inclusivity, with university programs faring better than private institutions [41]. Though program websites remain the most utilized electronic resource, more recently, SM influence appears to have increased. McHugh et al. published about the role of Facebook in 2014, with nearly half of the anesthesia residency candidates for their institution using it during the interview process [42]. Due to the creation of newer social media platforms and the restrictions enacted due to the COVID19 pandemic, this was a hot topic at the 2021 Association of Program Directors in Surgery (APDS) meeting. An abstract presented by Bludevich from the University of Massachusetts evaluated the increase in social media accounts and posts by surgery departments and surgery residency programs. An extensive amount of literature on the use and impact of $\mathrm{SM}$ is expected to materialize over the next year.

The importance of SM has already been evaluated in plastic surgery programs. In one study from 2021 that surveyed plastic surgery resident applicants, $60 \%$ of responders reported using social media. Though $72 \%$ of applicants said a program's poor SM presence did not make them lose interest in a program, for those candidates who did lose interest based on SM, the factors that were reported were infrequent posts, outdated content, and lack of engagement [43]. In 2020, Azoury et al. found that Facebook is still the most popular platform, followed by Instagram and Twitter. The use of these platforms varies from personal to professional. However, "training program 
social media use is rising, with Instagram and Twitter presence growing at exponential rates" [44]. In a study evaluating plastic surgery applicants to Harvard, the authors found that $97 \%$ of applicants used SM for information gathering, but only twenty percent of respondents' program rank list was influenced by a program's SM. Additionally, the majority of respondents trusted the SM information as accurate only most of the time [39]. What content applicants find most important on SM is still controversial, with some studies finding respondents looking for resident life information and others seeking posts about educational or clinical information [39, 40, 44].

Traditionally, most programs hold a preinterview dinner followed by interviews the following day. In a survey of a single institution's fourth year medical students, Schlitzkus et al. found that $86 \%$ of applicants found the preinterview session informative about the program [45]. This is likely due to being able to appreciate the subjective factors that applicants consider important when selecting a program, such as resident life, "fit," and environment [35-37, 45]. As the pandemic halted in-person interviews, programs adapted in various virtual ways-hosting open house sessions, preinterview group interactions and interviews. Literature is just now emerging evaluating the financial differences to applicants and institutions. We have yet to see which of these practices will continue or be abandoned as we return to tried and tested processes. The programmatic implications of both virtual interviews and distanced medical school learning for nearly a year will likely not be appreciated for years, though altered attrition rate, specialty preference, and lack of comfort with procedures due to decreased exposure are possible consequences [46].

\section{Conclusion}

Beyond adequate acquisition of knowledge, the term "successful resident" has different implications based on residency program initiatives. There is ample literature about different aspects of the process, but onus is on the program to determine its assets, expectations and ambitions. Recognizing and highlighting individual program strengths will then allow applicants to match their needs to the program in more synergistic ways. It is necessary to make this information easily available to residency candidates. Currently, websites are the most utilized resource, but SM has increasing importance. Candidate assessment in addition to traditional application information may aid in adapting the screening and interview process. Undoubtedly, the COVID-19 pandemic has increased the complexity of the resident selection process in ways not yet completely delineated.
Funding No funding was received to assist with the preparation of this manuscript.

Data Availability Not applicable.

Code Availability Not applicable.

\section{Compliance with Ethical Guidelines}

Conflict of interest The authors have no relevant financial or nonfinancial interests to disclose, and no funding was received to assist with the preparation of this manuscript.

\section{References}

Papers of particular interest, published recently, have been highlighted as:

- Of importance

•• Of major importance

1. Dodson TF, Webb AL. Why do residents leave general surgery? The hidden problem in today's programs. Curr Surg. 2005;62(1):128-31. https://doi.org/10.1016/j.cursur.2004.07.009.

2. Longo WE, Seashore J, Duffy A, Udelsman R. Attrition of categoric general surgery residents: results of a 20-year audit. Am J Surg. 2009;197(6):774-8. https://doi.org/10.1016/j.amjsurg.2008. 06.038 .

3. - Abelson JS, Sosa JA, Symer MM, Mao J, Michelassi F, Bell R, Sedrakyan A, Yeo HL. Association of expectations of training with attrition in general surgery residents. JAMA Surg. 2018;153(8):712-7. https://doi.org/10.1001/jamasurg.2018.0611. Survey of resident expectations when entering training in 2007-08 compared to attrition. Despite changes in training paradigms, residents with realistic expectations of post-resident life were more likely to complete training.

4. Preece RA, Cope AC. Are surgeons born or made? A comparison of personality traits and learning styles between surgical trainees and medical students. J Surg Educ. 2016;73(5):768-73. https:// doi.org/10.1016/j.jsurg.2016.03.017.

5. Symer MM, Abelson JS, Wong NZ, Mao J, Michelassi F, Bell R, Sosa JA, Yeo HL. Impact of medical school experience on attrition from general surgery residency. J Surg Res. 2018;232:7-14. https://doi.org/10.1016/j.jss.2018.06.002.

6. Thomas JH. The surgical personality: fact or fiction. Am J Surg. 1997;174(6):573-7. https://doi.org/10.1016/s00029610(97)00208-0.

7. - Hoffman BM, Coons MJ, Kuo PC. Personality differences between surgery residents, nonsurgery residents, and medical students. Surgery. 2010;148(2):187-93. https://doi.org/10.1016/j. surg.2010.04.005. Medical students and residents of different specialties completed personality testing. Generally, surgery residents have significant personality differences compared to the other cohorts evaluated, which could be utilized in the recruitment process.

8. Foster KN, Neidert GP, Brubaker-Rimmer R, Artalejo D, Caruso DM. A psychological profile of surgeons and surgical residents. J Surg Educ. 2010;67(6):359-70. https://doi.org/10.1016/j.jsurg. 2010.07.007. 
9. Burkhart RA, Tholey RM, Guinto D, Yeo CJ, Chojnacki KA. Grit: a marker of residents at risk for attrition? Surgery. 2014;155(6):1014-22. https://doi.org/10.1016/j.surg.2014.01. 015.

10. Salles A, Lin D, Liebert C, Esquivel M, Lau JN, Greco RS, Mueller C. Grit as a predictor of risk of attrition in surgical residency. Am J Surg. 2017;213(2):288-91. https://doi.org/10. 1016/j.amjsurg.2016.10.012.

11. Hughes BD, Perone JA, Cummins CB, Sommerhalder C, Tyler DS, Bowen-Jallow KA, Radhakrishnan RS. Personality testing may identify applicants who will become successful in general surgery residency. J Surg Res. 2019;233:240-8. https://doi.org/ 10.1016/j.jss.2018.08.003

12. de Virgilio C, Yaghoubian A, Kaji A, et al. Predicting performance on the American Board of Surgery qualifying and certifying examinations: a multi-institutional study. Arch Surg. 2010;145(9):852-6. https://doi.org/10.1001/archsurg.2010.177.

13. • Shellito JL, Osland JS, Helmer SD, Chang FC. American Board of Surgery examinations: can we identify surgery residency applicants and residents who will pass the examinations on the first attempt? Am J Surg. 2010;199(2):216-22. https://doi.org/ 10.1016/j.amjsurg.2009.03.006. In an analysis of available resident candidate data and board passage rate, there are significant objective predictors of first time ABS pass rate.

14. Spurlock DR Jr, Holden C, Hartranft T. Using United States Medical Licensing Examination( $\left({ }^{\circledR}\right)$ (USMLE) examination results to predict later in-training examination performance among general surgery residents. J Surg Educ. 2010;67(6):452-6. https://doi.org/10.1016/j.jsurg.2010.06.010.

15. Elkbuli A, Kinslow K, Liu H, Senkowski C, Naveed I, Heidi B, McGuire E, Ang D. USMLE scores and clinical rotation role in predicting ABSITE performance among surgery interns. J Surg Res. 2020;247:8-13. https://doi.org/10.1016/j.jss.2019.10.048.

16. Cassidy DJ, Chakraborty S, Panda N, McKinley SK, Mansur A, Hamdi I, Mullen J, Petrusa E, Phitayakorn R, Gee D. The surgical knowledge "Growth Curve": Predicting ABSITE scores and identifying “At-Risk” residents. J Surg Educ. 2021;78(1):50-9. https://doi.org/10.1016/j.jsurg.2020.06.038.

17. Surgery Program Requirements. In: ACGME. 2020. https://www. acgme.org/Specialties/Program-Requirements-and-FAQs-andApplications/pfcatid/24/Surgery/. Accessed 14 May 2021.

18. Rozenshtein A, Mullins ME, Marx MV. The USMLE Step 1 Pass/Fail reporting proposal: The APDR position. Acad Radiol. 2019;26(10):1400-2. https://doi.org/10.1016/j.acra.2019.06.004.

19. Gardner AK, Cavanaugh KJ, Willis RE, Dunkin BJ. If you build it, will they come? Candidate completion of preinterview screening assessments. J Surg Educ. 2019;76(6):1534-8. https:// doi.org/10.1016/j.jsurg.2019.05.006.

20. Rajesh A, Asaad M. Alternative strategies for evaluating general surgery residency applicants and an interview limit for MATCH 2021: An impending necessity. Ann Surg. 2021;273(1):109-11. https://doi.org/10.1097/SLA.0000000000004501.

21. Alterman DM, Jones TM, Heidel RE, Daley BJ, Goldman MH. The predictive value of general surgery application data for future resident performance. J Surg Educ. 2011;68(6):513-8. https://doi. org/10.1016/j.jsurg.2011.07.007.

22. Papp KK, Polk HC Jr, Richardson JD. The relationship between criteria used to select residents and performance during residency. Am J Surg. 1997;173(4):326-9. https://doi.org/10.1016/ s0002-9610(96)00389-3.

23. Tolan AM, Kaji AH, Quach C, Hines OJ, de Virgilio C. The electronic residency application service application can predict accreditation council for graduate medical education competency-based surgical resident performance. J Surg Educ. 2010;67(6):444-8. https://doi.org/10.1016/j.jsurg.2010.05.002.
24. Stephenson-Famy A, Houmard BS, Oberoi S, Manyak A, Chiang S, Kim S. Use of the Interview in Resident Candidate Selection: A Review of the Literature. J Grad Med Educ. 2015;7(4):539-48. https://doi.org/10.4300/JGME-D-14-00236.1.

25. Kim RH, Gilbert T, Suh S, Miller JK, Eggerstedt JM. General surgery residency interviews: are we following best practices? Am J Surg. 2016;211(2):476-481.e3. https://doi.org/10.1016/j. amjsurg.2015.10.003.

26. Kiraly L, Dewey E, Brasel K. Hawks and Doves: Adjusting for Bias in Residency Interview Scoring. $J$ Surg Educ. 2020;77(6):e132-7. https://doi.org/10.1016/j.jsurg.2020.08.013.

27. Fryer JP, Corcoran N, George B, Wang E, Darosa D. Does resident ranking during recruitment accurately predict subsequent performance as a surgical resident? J Surg Educ. 2012;69(6):724-30. https://doi.org/10.1016/j.jsurg.2012.06.010.

28. Farkas DT, Nagpal K, Curras E, Shah AK, Cosgrove JM. The use of a surgery-specific written examination in the selection process of surgical residents. J Surg Educ. 2012;69(6):807-12. https://doi. org/10.1016/j.jsurg.2012.05.011.

29. Kelz RR, Mullen JL, Kaiser LR, Pray LA, Shea GP, Drebin JA, Wirtalla CJ, Morris JB. Prevention of surgical resident attrition by a novel selection strategy. Ann Surg. 2010;252(3):537-41. https://doi.org/10.1097/SLA.0b013e3181f27a50.

30. Stain SC, Hiatt JR, Ata A, Ashley SW, Roggin KK, Potts JR, Moore RA, Galante JM, Britt LD, Deveney KE, Ellison EC. Characteristics of highly ranked applicants to general surgery residency programs. JAMA Surg. 2013;148(5):413-7. https://doi. org/10.1001/jamasurg.2013.180.

31. Jarman BT, Joshi AR, Trickey AW, Dort JM, Kallies KJ, Sidwell RA. Factors and influences that determine the choices of surgery residency applicants. J Surg Educ. 2015;72(6):e163-71. https:// doi.org/10.1016/j.jsurg.2015.05.017.

32. Phitayakorn R, Macklin EA, Goldsmith J, Weinstein DF. Applicants' self-reported priorities in selecting a residency program. J Grad Med Educ. 2015;7(1):21-6. https://doi.org/10.4300/ JGME-D-14-00142.1.

33. • Ishida Y, Hosoya Y, Sata N, Yasuda Y, Lefor AT. Educational factors outweigh the importance of lifestyle factors for residency program applicants: an international comparative study. J Surg Educ. 2012;69(2):167-72. https://doi.org/10.1016/j.jsurg.2011. 07.009. Based on survey results from Japanese and US residents and students, educational factors still dominate lifestyle factors in resident program selection.

34. Simmonds AC 4th, Robbins JM, Brinker MR, Rice JC, Kerstein MD. Factors important to students in selecting a residency program. Acad Med. 1990;65(10):640-3. https://doi.org/10.1097/ 00001888-199010000-00009.

35. Zuo KJ, Retrouvey H, Wanzel KR. Factors that affect medical students' perception and impression of a plastic surgery program: The role of elective rotations and interviews. Ann Plast Surg. 2019;82(2):224-8. https://doi.org/10.1097/SAP. 0000000000001525 .

36. Stefanidis D, Miles WS, Greene FL. Factors influencing residency choice of general surgery applicants-how important is the availability of a skills curriculum. J Surg Educ. 2009;66(6):325-9. https://doi.org/10.1016/j.jsurg.2009.06.004.

37. Parker AM, Petroze RT, Schirmer BD, Calland JF. Surgical residency market research-what are applicants looking for? J Surg Educ. 2013;70(2):232-6. https://doi.org/10.1016/j.jsurg.2012.09. 002.

38. Embi PJ, Desai S, Cooney TG. Use and utility of Web-based residency program information: a survey of residency applicants. J Med Internet Res. 2003;5(3): e22. https://doi.org/10.2196/jmir. 5.3.e22.

39. •• Irwin TJ, Riesel JN, Ortiz R, Helliwell LA, Lin SJ, Eberlin KR. The impact of social media on plastic surgery residency 
applicants. Ann Plast Surg. 2021;86(3):335-9. https://doi.org/10. 1097/SAP.0000000000002375. Despite growing importance of social media for resident applicant evaluation of a residency, the program website remains the most important resource. However, websites were generally felt to be inadequate.

40. Ruddell JH, Tang OY, Persaud B, Eltorai AEM, Daniels AH, Ng $\mathrm{T}$. Thoracic surgery program websites: Bridging the content gap for improved applicant recruitment. J Thorac Cardiovasc Surg. 2020. https://doi.org/10.1016/j.jtcvs.2020.06.131.

41. Driesen AMDS, Romero Arenas MA, Arora TK, Tang A, Nfonsam VN, O'Grady CL, Riall TS, Morris-Wiseman LF. Do general surgery residency program websites feature diversity? J Surg Educ. 2020;77(6):e110-5. https://doi.org/10.1016/j.jsurg. 2020.06.01.

42. McHugh SM, Shaffer EG, Cormican DS, Beaman ST, Forte PJ, Metro DG. Use of social media resources by applicants during the residency selection process. J Educ Perioper Med. 2014;16(5):E071.
43. Duque S, Riccelli V, Mulqueen S, Zhang AY. Global pandemic and PRS residency match: Can social media fill the void? Aesthet Surg J. 2021. https://doi.org/10.1093/asj/sjab222.

44. Azoury SC, Mazzaferro DM, Piwnica-Worms W, Messa CA 4th, Othman S, Stranix JT, Serletti JM, Kovach SJ, Fosnot J. An update on social media in academic plastic surgery training programs: the rising trend of likes, shares, and retweets. Ann Plast Surg. 2020;85(2):100-4. https://doi.org/10.1097/SAP. 0000000000002289.

45. Schlitzkus LL, Schenarts PJ, Schenarts KD. It was the night before the interview: perceptions of resident applicants about the preinterview reception. J Surg Educ. 2013;70(6):750-7. https:// doi.org/10.1016/j.jsurg.2013.05.008.

46. Sell NM, Qadan M, Delman KA, Roggin KK, Spain DA, Phitayakorn R, Lillemoe KD, Mullen JT. Implications of COVID-19 on the general surgery match. Ann Surg. 2020;272(2):e155-6. https://doi.org/10.1097/SLA.0000000000004032.

Publisher's Note Springer Nature remains neutral with regard to jurisdictional claims in published maps and institutional affiliations. 